\title{
TORSION UTERUS DUE TO FIBROID- ONCE IN A BLUE MOON!!!
}

R. Sankareswari

\section{Assistant Professor, Department of Obstetrics \& Gynaecology, IRT, Perundurai Medical College.}

\section{CORRESPONDING AUTHOR}

Dr. R. Sankareswari M.D, DGO, Ficog,

Assistant Professor, IRT - Perundurai Medical College

Erode Pin -6380531.

E-mail: mlrsreekrishna@yahoo.com, Ph: 00919443371986.

ABSTRACT: Torsion due to fibromatous uterus is a very rare entity. Worldwide there are only a few references. This case is $138^{\text {th }}$ case of uterine torsion due to fibroid as per literature. A case of huge fibromatous uterus weighing $4 \mathrm{~kg}$ undergone axial torsion through 360 degrees to the right, diagnosed at laparotomy, in a 63 years aged woman with the clinical symptoms of bleeding pv and abdominal pain for 4 days duration. Examination of the abdomen revealed a non-tender, mobile mass of size $20 \times 17 \mathrm{~cm}$, firm in consistency, arising from pelvis, corresponding to 32 weeks gravid uterus. Ultrasound examination of abdomen and pelvis showed fibroid picture and the patient treated by total abdominal hysterectomy with bilateral salpingo-oophorectomy. At operation, there was a 360 degree clockwise twisting of the uterine mass at the level of cervical isthmus, carrying with it both tubes and ovaries. The uterus was filled with huge intramural fibroid and the specimen sent for histo-pathological examination was proved to be fibroleiomyoma. Torsion of non-pregnant uterus due to fibroid alone is extremely rare and hence this case reported for its rarity.

KEY WORDS: torsion, fibroid.

INTRODUCTION: Torsion uterus due to fibroid uterus is extremely rare and rarely reported. Here is a report of an interesting case of torsion uterus due to fibroid in a post-menopausal woman.

CASE REPORT: Mrs. X, 63 year old, post -menopausal woman admitted with complaints of bleeding PV and abdominal pain for 4 days. She gave history of abdominal pain for 2 months. She had no urinary or gastrointestinal symptoms. She is a known hypertensive and diabetic under good control with treatment for the past 4 years. She attained menarche at $14^{\text {th }}$ year and menopause at 52 years. Before menopause her periods were regular. She is Para 2 Live 2 . Her vitals were normal. Abdominal examination revealed a mass arising from pelvis extending above the umbilicus, $25 \mathrm{~cm}$ from pubic symphysis, $10 \mathrm{~cm}$ from midline on either side, corresponding to 32 weeks gravid uterus, regular, firm, mobile, not tender. Lower border is felt and able to get below the swelling. Liver and spleen were not palpable. Hernial orifices were free. There was no free fluid. On speculum examination revealed that cervix flushed with vault and found to be normal. Minimal bleeding through os was present. Cervical smear taken and study was normal. On vaginal examination: Uterus not made out separately. Swelling felt through fornices. Not tender. USG abdomen pelvis revealed fibroid picture. Endometrial 
thickness was not measurable. Ovaries not visualized separately. Liver, spleen, pancreas, kidneys were normal. Differential diagnosis went in favor of

1. Ovarian tumor (fibroma ovary) with torsion - because of mobility and age.

2. Fibroid uterus with degenerative changes- because of pain and ultrasound picture.

Laparotomy performed. Abdomen opened by right para-median incision. It was an exceptionally large fibroid uterus which had twisted to 360 degrees in clockwise direction at the level of cervix, carrying with it both tubes and small ovaries. Entire mass was congested, reddish blue with dilated vessels over it. After untwisting the mass, total abdominal hysterectomy and bilateral salpingo-oophorectomy performed and one unit of 0 positive blood was transfused. The specimen weighed $4 \mathrm{~kg}$ and measured $20 \times 17 \mathrm{~cm}$. The whole uterus was replaced with intra mural fibroid and there was supra vaginal elongation of cervix measuring $6 \mathrm{~cm}$. On cut section there was intense congestion and engorgement of the intra mural vessels with interstitial hemorrhage. Specimen sent for histo-pathological examination and proved as fibroleiomyoma.

DISCUSSION: In uterine torsion the uterus twists more than 45 degrees around its long axis at the junction between the cervix and the corpus. Cases involving twists of $60-720$ degrees have been reported. Some authors have shared their opinion regarding torsion of gravid uterus with fibroid that is more common than leiomyomatous uterine torsion. The rarity of uterine torsion has been pointed out by some authors- Hanley B.J ${ }^{1}$, McMurray C.S and Gayden,H.V 2 ,Nesbitt and Corner(1956) ${ }^{3}$ article in German (1980), Greece (2003), Bulgarian (2006). First case of torsion was reported in a postmortem finding in 1861- quoted by Adoni (1973) ${ }^{4}$ and mentioned by Krzaniak (1974) ${ }^{5}$. Torsion uterus grouped as

(1) Primary - when associated with primary mover like fibroid, ovarian tumor or

(2) Idiopathic, rather than according to pregnancy is present or not.

Uterine torsion may be associated with congenital weakness at the junction of cervix and uterus or pelvic adhesions or distortion of uterine shape due to uterine leiomyomas or large ovarian neoplasm or unknown etiology. Though uterine torsion can be asymptomatic, women may present with abdominal pain, gastrointestinal and urinary dysfunction, vaginal bleeding, sometimes even shock. Clinical suspicion should come first when there is abdominal pain with pregnancy or with abdominal mass. Torsion is diagnosed preoperatively in MRI if it involved upper vagina by ' $\mathrm{X}$ ' sign in MRI. Normally vagina appears $\mathrm{H}$ shaped. Definitive diagnosis is only by laparotomy. Total abdominal hysterectomy with bilateral salpingo-oophorectomy is the treatment.

\section{REFERENCES:}

1. Hanley B.J, Asymptomatic axial torsion of full-term uterus through 180 degrees.Amer J Obstet Gynec 1939; 38:164.

2. McMurray C.S and Gayden,H.V, Acute axial torsion of fibromatous uterus.J Amer Med Ass 1937; 108:709.

3. Nesbitt REL and Corner GW, Torsion of the human pregnant uterus. Obstet Gynec Surv 1956; 11:311-332.

4. Zuckerman $\mathrm{H}$ and Adoni A,Torsion of fibroid.Int.J.Gynaec Obstet 1973; 11:118-121. 
5. Krzaniak S, torsion of fibroid uterus resulting in profound shock, Europ.J. Obstet. Gynec. Reprod. Biol 1974; 4/1:41-43.

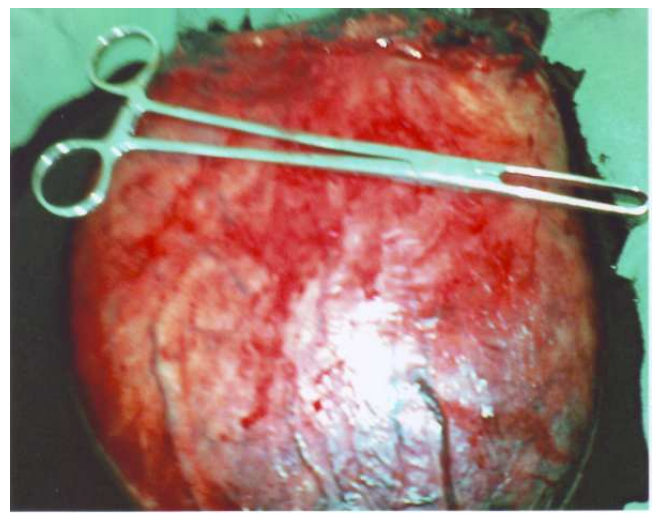

Fig.1. Showing size and intense congestion

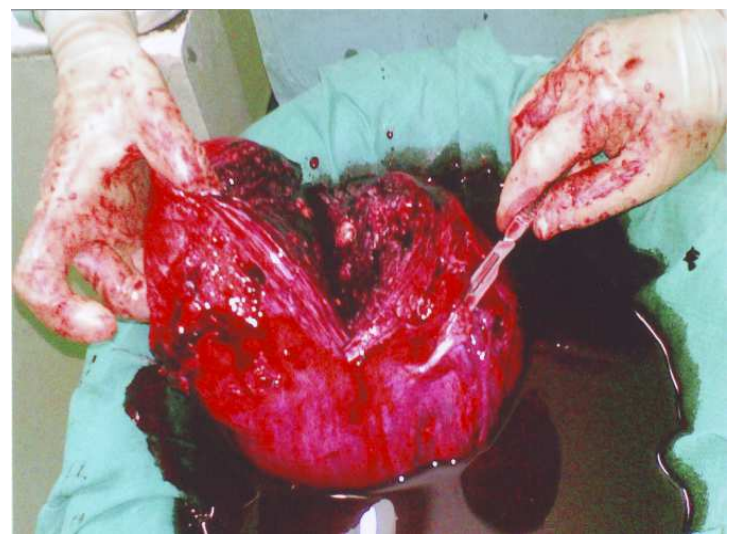

Fig.2.Showing ovaries and round ligament

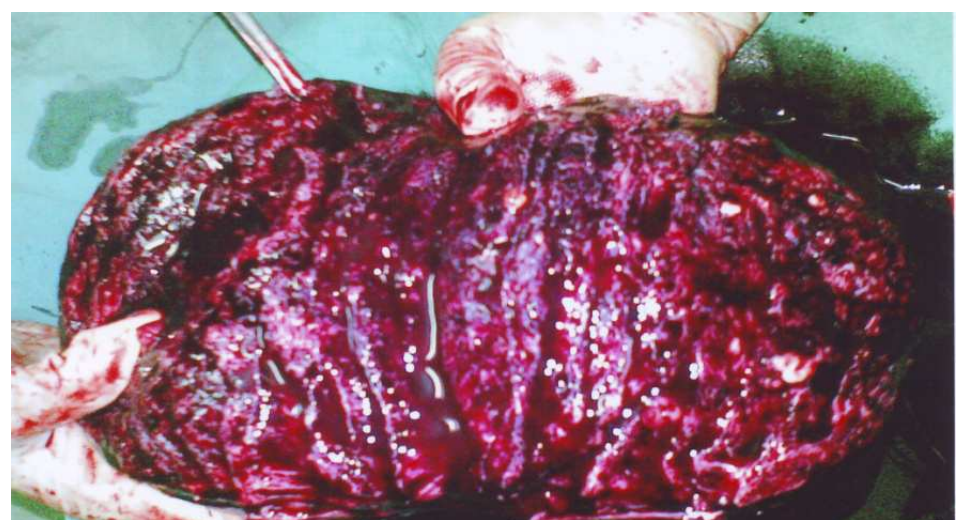

Fig.3. Intense congestion and engorgement of vessels with interstitial haemorrhage 